\title{
A celebração da vida na poesia de Cairo de Assis Trindade
}

Celebration of life in Cairo de Assis Trindade's poetry

Weslei Roberto Cândido

UEM

weslei79@gmail.com

RESUMO: O presente estudo se dedica à análise da poesia de Cairo Trindade no livro intitulado Poezya, que porra é essa?. A partir das considerações de Octavio Paz sobre a revelação poética, pretende-se mostrar o caráter de celebração da vida que se oculta sob um título aparentemente agressivo, para, no final das contas, descortinar uma poética da comunhão do homem com o Outro por meio da posse corporal. Esse aspecto corpóreo na poesia de Trindade permite ao leitor ver o corpo como o templo da poesia e da vida que nasce por meio dos versos. Dessa maneira, percebe-se que o livro em questão celebra a vida cotidiana e a alegria de viver em comunidade. A comunhão com o Outro é que permite chegar ao sagrado e mudar a maneira de olhar o mundo.

Palavras-chave: Poesia. Revelação. Corpo. Celebração. Sagrado.

ABASTRACT: The present study aims to analyse Cairo Trindade's poetry in the book entitled Poezya, que porra é essa?. From Octavio Paz's considerations on poetics revelation, we intend to show the features of celebration of life which are occluded under an apparently aggressive title, to, in the end, uncover a poetics of human communion with the Other through corporeal possession. Such corporeal aspect on Trindade's poetry allows the reader to regard the body as the temple of poetry and life which is born through the verses. This way, we realize that the book under study celebrates daily life and the joy of living in community. The communion with the Other is the one which allows to reach the sacred and change the way of seeing the world.

Keywords: Poetry. Revelation. Body. Celebration. Sacred. 


\section{Introdução}

O presente ensaio tem como proposta de trabalho tratar a revelação poética como forma de comunhão com o Outro na poesia de Cairo Trindade. Para tanto, os estudos de Octavio Paz em $O$ arco e a lira (2012) servirão de base para se construir um caminho interpretativo do trabalho poético de Trindade, mais especificamente em seu livro Poezya, que porra é essa?, publicado no ano de 2011.

Nossa hipótese de trabalho se baseia no caráter celebrativo da vida existente no livro citado acima. Embora o título seja agressivo, use palavra de baixo calão ou, pelo menos, de cunho sexual, o conteúdo do volume desmente essa postura de escracho. Em suas poesias Cairo Trindade revela um intenso desejo de compartilhar com o Outro seus sentimentos, sua vida, sua forma de ver o mundo.

O questionamento presente no título mostra a visão do poeta em relação ao que pode ser considerado poesia, quais são os objetos ou temas dignos da confecção poética. Subvertendo as regras da Língua Portuguesa, o poeta grafa poesia com "z" e " $y$ ", mostrando ao leitor a proposta de desrespeitar as regras não só gramaticais, mas daquilo que se consagrou como digno de poeticização.

Portanto, desde o título do livro há uma política do "baixo ventre", com um vocabulário que atira à face do leitor um termo considerado baixo, vulgar: "porra"; tudo isso por meio de uma linguagem coloquial, que pretensamente exige para si o direito de também ser poesia. O poeta também desrespeita outras normas da Língua Portuguesa, registrando todos os poemas em letras minúsculas, independentemente do local de ocorrência do vocabulário.

Revista Texto Poético | ISSN: 1808-5385 | Vol. 18 (10 sem-2015) - p. 163 
O poema de abertura do livro usa termos em latim, centralizando a palavra "mix" em torno da qual giram outros vocábulos latinos como "Pax", "Vox", "Sex" e "Lux",

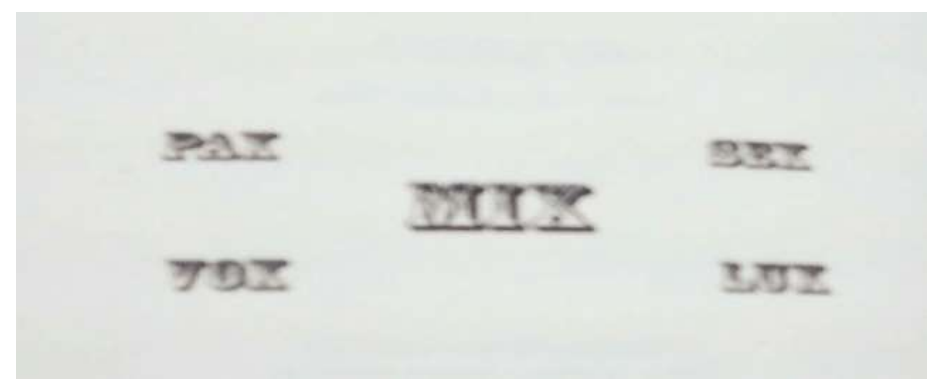

(TRINDADE, 2011, p. 8).

que autorizam a suposição de que a poesia é uma forma de iluminação do homem, é uma das categorias do sagrado, tem voz, paz, é sexo e luz. Na poesia o homem se encontra com o homem em seu estado primitivo de necessidades básicas como falar, ter paz, ter sexo e encontrar a iluminação nesse caminho de ascese, que encontra na poesia uma das pontes para o conhecimento de si e do Outro. É desse "mix" essa mistura de paz, sexo, fala e iluminação que se constitui a poesia no livro de Trindade.

Parte-se de uma pretensa falta de respeito com a poesia para, na verdade, sacralizar termos sexuais dentro do ambiente poético. $\mathrm{O}$ corpo se torna um referente a ser explorado, conhecido. O sexual se transforma em uma categoria de revelação do sagrado e da poesia no processo de autoconhecimento empreendido pelo homem.

Ainda sobre esse aspecto do baixo ventre, como estratégia de sacralização na poesia de Trindade, temos os versos de "criação momento mágico", nos quais percebe-se como o poético também

Revista Texto Poético | ISSN: 1808-5385 | Vol. 18 (10 sem-2015) - p. 164 
está nas fezes: "meu barato e dejeto / minuto mais secreto / meu último reduto" (TRINDADE, 2011, p. 12), participam do momento de criação literária. "Barato" e "dejeto" estão no mesmo nível, ambos participam do momento de inspiração poética.

Nesse sentido pode-se ligar a poesia de Trindade a uma tradição rabelaisiana da literatura da Idade Média, quando o grotesco era uma forma de criação, em que o baixo ventre, as fezes, a morte e a velhice eram temas que se renovavam por meio do riso. Riso regenerador, capaz de dar vida, de mostrar ao homem o caráter vivificador através de elementos considerados baixos pela tradição séria da sociedade, fortemente marcada por um caráter religioso coercitivo.

De acordo com Bakhtin

O realismo grotesco e a paródia medieval baseiam-se nessas significações absolutas. Rebaixar consiste em aproximar da terra, entrar em comunhão com a terra concebida como princípio de absorção, e ao mesmo tempo nascimento: quando se degrada, amortalha-se e semeia-se simultaneamente, mata-se e dá vida em seguida, mais e melhor. Degradar significa entrar em comunhão com a vida da parte inferior do corpo, a do ventre e dos órgãos genitais, e portanto com atos como o coito, a concepção, a gravidez, o parto, a absorção de alimentos e a satisfação de necessidades naturais. A degradação cava o túmulo corporal para dar lugar a um novo nascimento. E por isso não tem somente um valor destrutivo, negativo, mas também positivo, regenerador: é ambivalente, ao mesmo tempo negação e afirmação. Precipita-se não apenas para o baixo, para o nada, a destruição absoluta, mas também para o baixo produtivo, no qual se realizam a concepção e $o$ renascimento, e de onde tudo cresce profusamente. $O$ realismo grotesco não conhece outro baixo: o baixo é a terra que dá vida, e o seio corporal; o baixo é sempre o começo. (BAKHTIN, 1987, p. 19). 
O fazer poético de Cairo Trindade participa dessa concepção de vida em que o coito, a concepção, a satisfação de necessidades básicas são formas de o homem alcançar a comunhão com algo superior. O corpo, principalmente as partes da região do ventre, é capaz de colocar o homem em estado de regeneração com a vida. Descer à terra, à sexualidade quase instintiva é uma forma de realização espiritual e poética. $\mathrm{O}$ baixo, herdado desse realismo grotesco, é o caminho para a realização da poesia e responde à pergunta: "Poezya, que porra é essa?".

A poesia para Trindade é sexo, orgia com as palavras e com o universo. A revelação poética está muito próxima do gozo carnal. Em "pileque das palavras", o eu-lírico afirma, em estado de satisfação sexual, que o poema é vida e morte ao mesmo tempo, que sai "do poema como quem renasce / tonto e meio louco - quase sangro sempre / quase sempre gozo y sempre morro um pouco" (TRINDADE, 2011, p. 13). Assim, morte e vida estão no poema. Sexo, gozo violento, que faz o eu-lírico sangrar em meio à criação poética. Terminar o poema corresponde ao coito, que ao seu término mata um pouco seu compositor.

Essa relação corporal do poeta com as palavras percorre todo o livro. Mais adiante o eu-lírico desnuda sua relação com as palavras na poesia, quase a modo de receita: "não basta desnudar a palavra. / é preciso penetrá-la. e fazê-la gozar. / poesia é fodamental" (TRINDADE, 2011, p. 17). O poeta faz questão de negritar o último verso, explicitar que o ato poético é uma transa mental, mais que isso, uma foda mental, mais que fundamental, a poesia está no gesto de foder mentalmente. Dessa maneira, o poeta vai reafirmando sua 
relação sexual com as palavras. Fazer poesia é como fazer sexo para Cairo Trindade. Poesia e sexo são as faces de uma mesma moeda.

Nossa hipótese de celebração da vida na poesia de Trindade passa muito por esse campo semântico da sexualidade, do baixo ventre, de ecos desse realismo grotesco de que comenta Bakhtin. Descer não significa apenas morte, mas vida que vai ao encontro de um eterno recomeço; reside nesse ponto a poesia como revelação da vida, como apego a um estado primitivo que o homem vive na eterna nostalgia.

Por isso, para dar continuidade ao trabalho, exporemos alguns conceitos de revelação poética proposto por Octavio Paz em $O$ Arco e a lira (2012). Assim, será possível ver como a poesia, a religião, o sagrado e a iluminação estão associados em forma de revelação de mundo para o homem.

\section{A poesia como revelação de si}

A poesia opera sobre o mundo um efeito de revelação do desconhecido, do oculto, do místico. Nesse sentido, de acordo com Octavio Paz (2012), o fazer poético está sobre as bases de comunhão do homem com algo superior, como se fosse um sentido de religião presente no ser humano. No entanto, a poesia é uma forma de revelação interior, em que o próprio homem encontra nas palavras o caminho para a descoberta de si e do mundo.

Esse conhecimento não é externo ao homem, mas encontra-se no seu interior. Não há a necessidade de um deus ou uma religião específica. O caminho da liberdade em busca de uma ascese é particular e pessoal, está na necessidade do "salto", da superação do obstáculo que se configura a realidade cotidiana. Atravessar essa

Revista Texto Poético | ISSN: 1808-5385 | Vol. 18 (10 sem-2015) - p. 167 
margem do racional, do tempo linear e encontrar o caminho da superação do modo tradicional de ver a vida é um dos papéis da poesia.

Alcançar os níveis do sonho, do delírio, da (des)razão é fazer da poesia ponte para um mundo superior mediado pelas palavras. $\mathrm{O}$ signo verbal é o instrumento de nomeação de novos mundos. Nesse sentido, toda poesia tem o caráter genésico de criação de universos. Nela o poeta se torna um pouco deus de uma realidade, que exige do leitor as palavras para realizar o "salto" necessário à revelação poética.

A poesia guarda com o sagrado aspectos de autoconhecimento, a que todo ser humano se submete em determinado momento de sua existência:

O sagrado transcende a sexualidade e as instituições sociais em que se cristaliza. É erotismo, mas algo que transpassa o impulso sexual; é um fenômeno social, mas é outra coisa. O sagrado nos escapa. Ao tentar captá-lo, descobrimos que tem origem em algo anterior e que se confunde com o nosso ser. Outro tanto acontece com o amor e a poesia. As três experiências são manifestações que é a própria raiz do homem. Nas três pulsa a saudade de um estado anterior. E esse estado é a unidade, primitiva, do qual fomos separados, do qual estamos sendo separados a cada momento, constitui nossa condição original, à qual voltamos uma e outra vez. (PAZ, 2012a, p. 143).

A poesia proporciona ao homem essa busca do estado anterior, essa necessidade de comunhão com o mundo, mas também consigo. Captar a poesia que há no ser humano é uma atividade que tende a escapar ao controle lógico das relações sociais e religiosas. Nesse caso, a poesia também está muito próxima do sagrado, pois 
revela sentidos ocultos e de prazer que, necessariamente, não estão ligados à sexualidade; a erotização do corpo por meio das palavras sacraliza o ato sexual, transformando o poético em ponte para a revelação do estado primitivo do ser humano, anterior à palavra e de que paradoxalmente nos aproximamos por meio do jogo verbal que o poeta realiza na arquitetura de novos universos. Por isso, essa saudade do estado anterior, primitivo: a mesma palavra que revela também afasta o homem de seu objetivo.

Assim como o sagrado espanta o homem, a poesia também possui esse efeito estarrecedor. O homem tem uma eterna capacidade de se assombrar diante do divino, daquele mundo que desconhece. A poesia exerce uma função semelhante ao sagrado, pois desperta naquele que a lê um estado de assombro semelhante ao da revelação sagrada. A incógnita diante desse estado psíquico impulsionado pela poesia revela que o homem ainda está em busca de algo primitivo, anterior às suas formas de conhecimento tradicional. Segundo Octavio Paz,

Na criação poética é um pouco parecido: ausência e presença, silêncio e palavra, vazio e plenitude são estados poéticos tanto quanto religiosos e amorosos. Em todos eles os elementos racionais surgem ao mesmo tempo que os irracionais e só é possível separá-los com uma purificação ou interpretação posterior. Tudo isso nos leva a presumir que é impossivel afirmar que o sagrado constitui uma categoria a priori, irredutivel e original, da qual procedem outras. Cada vez que tentamos apreendê-la, descobrimos que aquilo que parecia distingui-la também está presente em outras experiências. O homem é um ser que se assombra; ao assombrar-se, poetiza, ama, diviniza. No amor há assombro, poetização, divinização e fetichismo. $O$ poetizar também brota do assombro e o poeta diviniza como o místico e ama como o apaixonado. Nenhuma dessas 
experiências é pura; em todas elas aparecem os mesmos elementos, sem que se possa dizer que um é anterior aos outros. (2012b, p. 149, grifo nosso).

Como se percebe o sagrado não é uma categoria de criação poética, ou de inspiração da mesma. O sagrado está para a poesia como outras experiências, que levam o homem a assombrar-se. Desse assombro nasce a poesia, o amor, o sexo, o misticismo. Mas esse processo está mais ligado à capacidade de o homem se assombrar diante de situações incompreensíveis, que permitem a divinização, a poetização, o fetiche. Desse conjunto de elementos nasce a revelação poética, é quando o poeta dá o "salto" e ultrapassa o olhar racional e lógico do homem contemporâneo, acostumado a racionalizar o mundo que o cerca.

\section{O assombro e a celebração de si no Outro}

É desse assombro natural do homem que vemos nascer a poesia celebrativa de Cairo Trindade. No livro Poezya, que porra é essa? (2011), o leitor encontra a celebração da vida, o mistério de se encontrar com o Outro, de ver Nele o sagrado, o místico, o religioso, o motivo para a poesia. Alegria e necessidade de comunhão com o Outro estão presentes em diversas de suas poesias.

Conhecido por ser um dissidente da poesia marginal do final dos anos de 1970, Cairo Trindade participou ativamente do movimento de arte pornô no Rio de Janeiro, nos primeiros anos da década de 1980. Nesse período, uma série de atividades públicas de declamação de poesias e caminhadas nudistas ocorreram na praia de Ipanema. Sexo e poesia se uniam como parte de um mesmo processo 
criador, que com certeza chocou a muitos dos espectadores das atividades realizadas pelo grupo.

Sobre este período a pesquisadora Bianca Tinoco registra:

Em fevereiro de 1980, um grupo de mulheres protestou na Praia de Ipanema em prol do topless, para que pudessem tomar sol em pé de igualdade com os homens, sem sexualizar os seios. A iniciativa não durou mais que um verão, devido às pressões da sociedade, mas foi acompanhada pelo Topless Literário, uma manifestação poética nas areias da praia, da qual Kac participou. Naquele ano, ele se tornou O Bufão do Escracho, um dos integrantes do grupo Gang, braço performático do Movimento de Arte Pornô. O coletivo também era formado por Cairo Assis Trindade (O Príncipe Pornô), Teresa Jardim (A Dama da Bandalha), Denise Trindade (A Princesa Pornô, mulher de Cairo), Sandra Terra (Lady Bagaceira), Ana Miranda (A Cigana Sacana), Cynthia Dornelles e as crianças Daniel e Joana Trindade (Os Surubins).

Em 1980 e 1981, a Gang realizou uma série de intervenções em praças, praias e teatros no Rio de Janeiro, incluindo uma série de encontros de poesia às sextas-feiras, na Cinelândia. As vivências e descobertas do grupo eram publicadas na revista Gang, com três edições até setembro de 1981. (TINOCO, 2010, p. 2).

O corpo se torna um espaço de celebração, de vida, de morte, encontros e desencontros que são tematizados na poesia de Cairo Trindade. O sexo e a erotização da palavra estão presentes na sua forma de composição literária. Dessa forma, a poesia de Trindade joga com elementos caros ao homem, como a sacralização do corpo e a dessacralização do mesmo por meio da palavra, que o revela instrumento para a poesia, para o sexo e para a comunhão entre os homens.

Revista Texto Poético | ISSN: 1808-5385 | Vol. 18 (1o sem-2015) - p. 171 
Assim, vê-se na poesia, um pouco desbocada de Trindade, essa busca pelo primitivo, pelo estado anterior de que o homem sente uma estranha nostalgia. Essa aproximação a esse estado quase do sagrado é possível por meio da poesia que celebra a vida e a alegria do encontro com o Outro. Para a poesia de Cairo Trindade, o estado de comunhão é fundamental para uma ascese que não é espiritual, mas que eleva o homem a um patamar superior ao comungar com o Outro o amor, a amizade, o desejo de se completar, que não pode ser um caminho isolado da humanidade.

Não se pode atribuir a consciência dessa busca do sagrado ou do primitivo a Cairo Trindade. De acordo com Octavio Paz (2012), após o processo realizado, a poesia criada, os versos organizados, é que podemos depreender esse processo. Aquele que busca não tem plena consciência de estar procurando o sagrado ou a poesia. Isso é uma atitude natural do homem. Somente a análise da poesia permite encontrar esse desejo primitivo plasmado em versos.

No poema "fodástica", dedicado a Denizis, a Princesa pornô e esposa do poeta, por exemplo, o eu-lírico parte de um suposto niilismo em relação aos mitos, às lendas, às leis que regem o mundo para uma celebração do encontro do homem com a mulher, quando se realiza uma forma de comunhão quase religiosa por meio do contato dos corpos:

não acredito em cegonha, papai noel, natal, ano novo. não acredito em políticos, em reis, na leis, nos mitos.

creio em ti porque em ti me vejo

e me encontro comigo mesmo.

e só assim creio em mim, 
pois em mim não minto

o que sinto por ti quando te vejo,

quando te abraço, quando te beijo.

(TRINDADE, 2011, p. 9).

A primeira estrofe do poema reitera o advérbio "não", marcando de forma contundente a desilusão com as ideias comuns e estereotipadas da sociedade. Começa-se pela velha história contada às crianças sobre o nascimento: a cegonha que traz os bebês; passa por símbolos como "papai noel", que remete ao Natal e ilude as crianças com a figura do bom velhinho. Também conceitos temporais como "ano novo", pura convenção de calendário, que auxilia os homens a se organizar no tempo e no espaço, são postos em xeque pelo eu-lírico, que faz questão de grafar todo o poema em letras minúsculas, até mesmo quando a regra exige o uso da letra maiúscula. Dessa maneira, a estrutura do poema é uma forma de reforçar a desilusão do eu-lírico com as regras e convenções estabelecidas pelos manuais de gramática e pelo mundo em que vive.

O eu-lírico também partilha com a maioria da sociedade a desilusão em outras figuras públicas como os políticos e os reis. Também desconfia das leis e dos mitos, nada para o eu-lírico está livre de seu sentimento niilista em relação às regras criadas pela sociedade para o bom convívio.

No entanto, a segunda estrofe abandona o niilismo dedicado às figuras tidas quase como sagradas pela sociedade para entrar em comunhão com o Outro, com o corpo que se constrói à frente do eulírico. Aqui começa a celebração da vida, do homem em comunhão com a mulher. Desse sentimento de encontro, nasce a fé que faltava na primeira estrofe. O poema faz do corpo da mulher espaço de culto e de autoconhecimento. 
O sexo, esse ritual tão antigo da humanidade, ganha contornos de um momento genésico. O homem no ato sexual se realiza, renasce, encontra-se, recupera a fé em si e no Outro, pois pode tocar, beijar. Nesse instante não há mentira, mas o momento da descoberta, da comunhão: "e me encontro comigo mesmo / e só assim creio em mim" (TRINDADE, 2011, p. 9).

O corpo do Outro permite ao eu-lírico recuperar a fé em si. Esse caminho da revelação não é percorrido sozinho na poesia de Cairo Trindade, o Outro é fundamental, necessário, sem ele não é possível realizar o "salto" e se conhecer. O corpo do ser amado evita a mentira: "pois em mim não minto / o que sinto por ti quando te vejo[...]" (TRINDADE, 2011, p. 9). Há nos versos uma preocupação em marcar o instante, o espaço temporal da revelação de si no Outro. A reiteração do advérbio de tempo "quando", repetido três vezes, pontua o momento da descoberta, que se dá no olhar, no abraço e no beijo; formas físicas que servem de ponte para o "salto" que levará ao sagrado, ao amor, à poesia.

Não se pode celebrar sozinho. A celebração remete à festa, à participação de mais de uma pessoa em um momento que se deseja comemorar. A ascese do homem em busca da revelação do mundo e de seus mistérios superiores necessita do Outro nesse caminho, que levará à vida plena. Em "sartreana ou desastre de sartre", o eu-lírico subverte o dito, já quase estereotipado, de Sartre de que "o inferno são os outros", para celebrar a vida em comunidade, em contato com as pessoas:

solidão

não faz bem

pra ninguém 
se o inferno

são os outros

o paraíso também.

(TRINDADE, 2011, p. 42).

Os versos são marcados por um forte coloquialismo, explicitando a proposta de celebrar, de festejar a união com o Outro. Os versos curtos aceleram esse encontro das pessoas. A primeira estrofe é taxativa ao se posicionar contra a "solidão", ela não é desejável para nenhum ser humano. Já a segunda estrofe explora a hipótese de admitir a assertiva de Sartre, porém, não descarta que o paraíso também "são os outros". É nítida a opção do eu-lírico pelo paraíso, alcançado pela comunhão com as pessoas, com a humanidade de uma forma geral.

A comunhão proposta pela poesia de Cairo Trindade encontra no corpo do Outro o auge da revelação paradisíaca. Há uma espécie de junção carnal, que leva os corpos ao prazer, ao desconhecido, àqueles instintos mais primários quando o homem se realiza. Na poesia "paraíso", o eu-lírico desfruta do prazer proporcionado pelo toque: "maravilha maravilha / tua mão - minha braguilha", e também oferta o prazer louvando com sua boca o corpo do ser amado: "maravilha maravilha / meu lábio - tua virilha" (TRINDADE, 2011, p. 19).

O paraíso para o eu-lírico não está distante, mas reside nesse jogo dos corpos que se tocam e se conhecem, permitindo-se ao prazer mútuo. A palavra "maravilha" se repete oito vezes ao longo do poema e sempre precede o verso que desemboca no corpo do eulírico ou da pessoa amada.

Nesse caminho de conhecimento pelo corpo, no qual ele se sacraliza por meio do ato sexual, o leitor perceberá que o sexo é uma 
forma de crescimento espiritual, de elevação. No poema "orgiastral (um tanto ou quanto tanka)", percebe-se que a poesia de Trindade compreende o mundo pela realização do ato sexual, no qual até mesmo os astros se erotizam nesse percurso de ascese mística por meio do corpo:

a lua se solta, lânguida,
as nuvens soltam suas plumas
e as estrelas soltam a franga.

na terra, zorra e escarcéu.

no céu, um clima bordel.

(TRINDADE, 2011, p. 21).

Há um clima de orgia que começa no céu, com a lua voluptuosa, iluminando a noite de sexo e alegria. A visão do céu, como um palco onde se desenrola a celebração sexual, propõe ao eulírico contemplar as nuvens em seu traje de gala, cheias de plumas, e as estrelas saindo de seu padrão estático e "liberando geral", "soltando a franga", permitindo-se às liberdades da noite e do sexo.

Esse clima contagia tanto o céu quanto a terra. E nos dois espaços a orgia acontece. No alto e sublime e no baixo e terreno a sexualidade aflora na noite. Pela proposta do poema, os atos orgíacos são regidos pelos astros. O título já revela essa regência: "orgiastral". Se os astros se sexualizam, os homens, regidos por esse ambiente, também participam da festa: "na terra, zorra e escarcéu". Há uma bagunça sexual que celebra a sexualidade.

E se na terra reina a confusão, os ruídos sexuais, os alaridos de prazer, no céu o "clima de bordel" se esparrama. Na verdade, não há diferença entre o céu e a terra, ambas se unem na orgia. O sexo é $o$ elemento unificador entre $o$ alto e o baixo, entre o sagrado e o

Revista Texto Poético | ISSN: 1808-5385 | Vol. 18 (10 sem-2015) - p. 176 
terreno ou profano. O caminho que encontramos para igualar o céu e terra é a poesia, que serve como mediadora desse prazer que esbarra no sagrado e no profano.

Para Octavio Paz,

$O$ horror ao sagrado vem da estranheza radical. $O$ assombro provoca uma espécie de diminuição do eu. Quando se vê sozinho, o homem se sente pequeno, perdido na imensidão. A sensação de pequenez pode chegar à afirmação da miséria: o homem não passa de "pó e cinza". (PAZ, 2012c, p. 150).

No entanto, na poesia "orgiastral", o sagrado não é respeitado, nem o homem se sente pequeno diante da grandeza do céu. O sexo, a orgia, a junção dos astros e dos homens por meio da sexualidade abusada, em que reina a alegria e o gozo, aproximam os opostos: céu e terra. E, nessa orgia, o clima de celebração sexual vem do céu à terra e vice-versa. Na terra "escarcéu" e no céu "bordel".

Portanto, percebe-se nessa poesia a dessacralização do céu por meio do sexo. Ele funciona como elemento libertador do homem, que pode viver sua sexualidade plenamente. $O$ céu, inclusive, participa dessa sexualidade aflorada. Os astros celebram com os homens a vida por meio do sexo.

Nessa jornada de autoconhecimento, mediado pela atividade sexual, na poesia de Cairo Trindade, o leitor se depara com o "jardim dos prazeres". Mais um poema onde a comunhão com o Outro, no caso com o corpo da mulher, leva à alegria e à vida, numa atitude quase ritual, em que o feminino se sacraliza no ato sexual:

Revista Texto Poético | ISSN: 1808-5385 | Vol. 18 (10 sem-2015) - p. 177 
teus seios, meus dois enleios

paz dos meus passeios

palco dos meus desejos

parque dos meus recreios

meus lábios loucos, sem freios

sugando o sumo em seus veios

teus seios, ah, os teus seios

meus mais sagrados anseios

oh, céus!, oh, cios! teus seios

bem os sei, já os saboreei-os

até em meus devaneios

(TRINDADE, 2011, p. 23).

A mulher nua figura aqui em seu porte de doadora da vida e do prazer. Seus seios encantam o eu-lírico e o mantêm em paz. Esse é o "jardim dos prazeres": os seios, que deixam seu adorador embevecido, emaranhado nesse corpo, que se converte em palco e em parque. Então, em um primeiro momento, o corpo é motivo de alegria, recreação, paz e o eu-lírico desfruta desses seios quase em uma atitude infantil, de retorno às origens, à infância.

Os seios alimentam os lábios do eu-lírico, que suga “o sumo em seus veios". Essa ambiguidade entre mulher e mãe aumenta ainda mais a força do sexo como forma de sacralização do corpo. Ao mesmo tempo fonte de nascimento e do renascimento do homem. Na forma feminina, o eulírico encontra o sagrado ou, melhor, nos seios dela estão seus "mais sagrados anseios".

A sonorização em "eio" que se repete ao longo de todo o poema: seios, enleios, passeios, recreios, freios, veios, devaneios", etc., marcam essa toada de uma ladainha em louvor aos seios da mulher amada. Quase 
um ciciar dos "cios" despertados por esse corpo, que amamenta o eulírico tanto física quanto espiritualmente: "sugando os sumos em seus veios" e "mais sagrados anseios", todas as necessidades da voz lírica são satisfeitas nos seios do ser amado.

Novamente, o corpo nu é objeto de culto, de celebração na poesia de Cairo Trindade. O Outro deve se fazer presente, o caminho não poderá ser trilhado só, mas em companhia de uma mulher, com quem o eu-lírico forma o casal e, só assim, é feliz. O livro Poezya, que porra é essa? cultua a comunhão com o Outro como forma de alcançar a felicidade.

A comunhão pelo sexo também se exibe em um poema concreto chamado "positions, 1981". As aspas formam posições sexuais até chegar ao amor. Parte-se de uma separação do par, porém se encerra na celebração do amor, do encontro entre as partes e, assim, se é possível ser feliz:

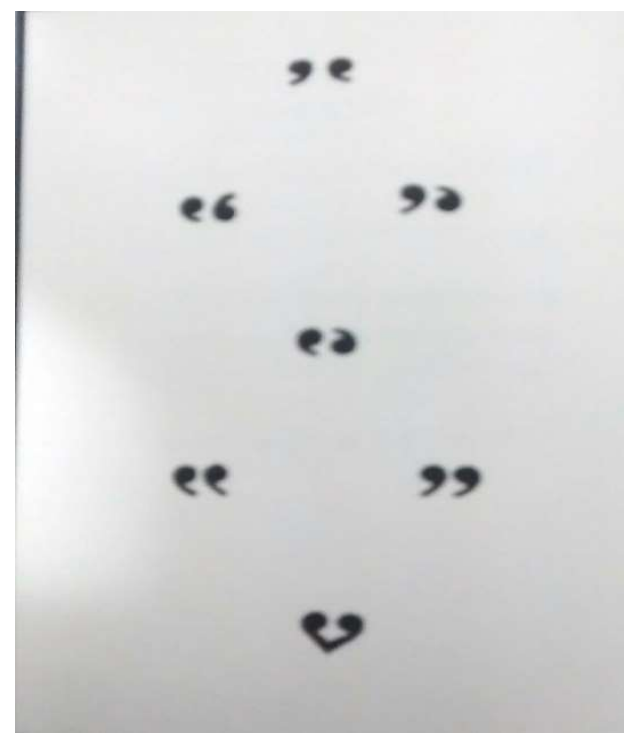

(TRINDADE, 2011, p. 22). 
Portanto, a poesia de Cairo Trindade exala a necessidade de comunhão, de encontro, de relacionamentos. Por meio desses últimos, o homem se realiza, encontra seu eu, não está mais abandonado nesse mundo cruel e de egoísmos. Nesse aspecto, a poesia, aparentemente marginal, cheia de marcas de coloquialismo, é neorromântica. Os poemas de Poezya, que porra é essa? têm uma forte crença no ser humano e na sua capacidade de desenvolver relacionamentos amorosos, nos quais o sexo é um elemento primordial.

Essa crença na vida também está em um poema intitulado "graça", (p. 40), no qual o eu-lírico faz um balanço de sua vida. Das contas realizadas, chega-se a um saldo positivo. A poesia, os sonhos, as mulheres que amou, o que deu, perdeu e sofreu, não há dúvidas: "pelo sim e pelo não / a vida não foi em vão" (TRINDADE, 2011, p. 40). O ponto de vista do eu-lírico é que viver foi compensador, "não foi em vão", valeu a pena ter sofrido, amado, ganhado ou perdido. Esses momentos fazem parte do jogo da vida.

Ao perseguir essa ideia de celebração na poesia de Cairo Trindade, procura-se mostrar o caráter ritual, de culto, presente em seus versos. O corpo é lugar santo e profano, espaço de libertação, de amor, de conhecimento, motivo de poesia. Dentro da tradição cristã ocidental, costumou-se tratar o corpo como casa, como templo. Com isso, não quer se afirmar que o poeta é um crente no sentido tradicional da palavra, ou que esteja preocupado com religião. Mas tem-se um tecido cultural, ao qual inevitavelmente os textos acabam por se submeter. No caso de Trindade, não é diferente. Veja-se o poema "casa cheia": 
onde andei, por onde vim, deixei pedaços de mim.

cada um que entra aqui

sai, deixa um pouco de si.

todos tecem suas teias

- virtuais, de nuvens, de veias.

há vários de nós entre nós:

jamais estamos tão sós.

(TRINDADE, 2011, p. 47).

Os encontros ao longo da vida do homem deixam marcas, criam sua história, sua biografia, dão sentido ao seu caminho. De acordo com o eu-lírico, os pedaços de seu corpo ficaram por onde ele passou. Não se passa impunemente pela vida das pessoas, por suas histórias, fragmentos do ser humano são compartilhados com o Outro. Os encontros marcam a partilha, e todos com quem se cruzou retiveram um pedaço do sujeito lírico.

O corpo no poema em questão vira casa, templo, local de parada, habitação, mesmo que momentânea de outros seres humanos, que não apenas o eu-lírico: "cada um que entra aqui / sai, deixa um pouco de si" (TRINDADE, 2011. p. 47). O corpo se torna lugar de passagem, visitação. Cada um dos passantes, deixou um pouco de si também, assim como o eu-lírico que, na primeira estrofe, afirma ter deixado pedaços seus por outras casas.

$\mathrm{O}$ aspecto espiritual da casa se marca na terceira estrofe, quando o eu-lírico comenta o tecer de "teias virtuais, de nuvens e de veias". Essas teias, de certo modo, deixam o ser humano preso ao outro. Sempre se tem um pouco de quem passou na vida do homem. 
Embora essas "teias" não sejam visíveis, elas formam o emaranhado que é o espiritual do ser humano.

Porém, o elemento mais importante do poema, que se revela na última estrofe, é que a "casa", o corpo do homem é o espaço de encontro, de culto, de compartilhamento de si com os demais seres humanos que visitaram esse templo, que é o corpo do eu-lírico. Esse fato permite ao homem nunca estar só, de ser vários, múltiplo, de ter em si, diversas personalidades que herdou dos visitantes de seu corpo: "jamais estamos tão sós", afirma a voz lírica ao final do poema.

Ao longo dos poemas lidos aqui, e também dos poemas do volume em análise neste estudo, percebe-se uma preocupação em nunca estar só, em reconhecer que a solidão é algo que não faz bem. Cairo Trindade trabalha uma poética do relacionamento, da comunhão, na qual o corpo é um elemento essencial. O corpo é a casa de encontro, é o templo, local de ritualização do amor e do sexo.

Nesse encontro com o Outro, nas relações estabelecidas, o mundo se revela, a poesia exerce sua função de mecanismo de ascese espiritual do homem. O texto poético é uma forma de liturgia, que permite ao homem encontrar-se com o sagrado, sem ter horror a ele. O sagrado na poesia de Trindade está no corpo do homem e da mulher. O ser humano ritualiza-se para revelar a alegria e um modo de viver sem desiludir-se tanto com o cotidiano.

Desta maneira, é possível afirmar que os poemas de Poezya, que porra é essa? traçam o percurso de celebração da vida, na qual o corpo é elemento indispensável. Sexo e vida se complementam nessa poesia, o ritual no culto exige a presença de mais de uma pessoa para ser celebrado. Cairo Trindade convoca o homem à comunhão, ao encontro. Estar só, nessa poética, seria a maior

Revista Texto Poético | ISSN: 1808-5385 | Vol. 18 (10 sem-2015) - p. 182 
tragédia do ser humano. Nota-se que a todo o custo a solidão é evitada nos poemas do livro em questão.

A opção pelo sexo, pelo baixo ventre, onde se localizam os órgãos sexuais, mostram toda a força criadora dessa poesia. A força genésica está na cópula dos indivíduos, no encontro dos corpos que se roçam, visitam-se, penetram-se e deixam um pouco de si em cada corpo. Como afirma o eu-lírico em "palavra - feito \& dito": "meu compromisso / é não ter nenhum compromisso / senão comigo / (e contigo)" (TRINDADE, 2011, p. 49). Pode-se afirmar, então, que a poesia de Cairo tem o compromisso com o homem, com a mulher, com o ser humano e seus encontros ao longo da vida.

\section{Considerações finais}

Ao longo deste pequeno ensaio procurou-se provar a tese de que há um caráter de celebração na poesia de Cairo Trindade. Esse culto, necessariamente, passa pelo corpo feminino e masculino em busca de comunhão com o Outro. O sexo se torna uma das formas de ascese espiritual, de autoconhecimento para o homem ao longo das experiências que adquire na vida.

$\mathrm{O}$ uso de coloquialismos, os desrespeitos às regras gramaticais, a subversão de ditos considerados canônicos aproximam a poesia do leitor, que também passa a compartilhar com o eu-lírico de uma visão de mundo alegre e festiva.

Nesse aspecto a poética de Poezya, que porra é essa? é neorromântica, pratica a fé na vida, nas pessoas, acredita na possibilidade de comunhão com o Outro em uma total liberdade. A poesia é uma forma de libertação do homem, que, em geral, vive preso aos ditames de uma sociedade tradicional. 
Ocorre, naturalmente, nessa estratégia poética, uma aproximação ao sagrado. Porém, estar diante desse elemento que, na visão de Octavio Paz, deveria causar horror e deixar o homem diminuído diante da grandeza do objeto sacro, na poesia de Cairo Trindade é motivo de celebração e festa, de orgia, algumas vezes. Céu e terra se misturam no ato sexual e há um festejar à noite entre os astros e os homens.

Portanto, ler a poesia de Cairo Trindade é um convite à festa, à celebração da vida, à comunhão do homem com o homem. Não é possível ser feliz estando só. Tomando de empréstimo as palavras do próprio poeta, já comentadas neste texto: "solidão / não faz bem / pra ninguém" (2011, p. 42). Então, resta apenas ao homem deixar-se envolver pelo Outro e caminhar ao longo da vida, por meio dessa poética do relacionamento, do coletivo, da vida em grupo; enfim, da comunhão com a humanidade, livre de preconceitos ou padrões pré-estabelecidos.

\section{Referências}

BAKHTIN, Mikhail. A cultura popular na Idade Média e no Renascimento: o contexto de François Rabalais. Trad. Yara Frateschi Vieira. São Paulo: HUCITEC; Brasília: Editora da Universidade de Brasília, 1987.

PAZ, Octavio. O arco e a lira. Trad. Ari Roitman e Paulina Wacht. São Paulo: Cosac Naify, 2012.

TINOCO, Bianca. Eduardo Kac e a escrita do corpo no espaço. In Concinnitas Ano 11, vol. 2, n. 17. Dezembro de 2010.

TRINDADE, Cairo de Assis. Poezya, que porra é essa? Rio de Janeiro: Personal, 2011. 